\title{
Inflammation as a Link between Obesity and Metabolic Syndrome
}

\author{
Faloia Emanuela, Michetti Grazia, De Robertis Marco, Luconi Maria Paola, \\ Furlani Giorgio, and Boscaro Marco
}

Division of Endocrinology, Polytechnic University of Marche, via Conca 71, 60126 Ancona, Italy

Correspondence should be addressed to Faloia Emanuela, e.faloia@univpm.it

Received 1 July 2011; Revised 19 October 2011; Accepted 3 November 2011

Academic Editor: H. Vannucchi

Copyright ( $) 2012$ Faloia Emanuela et al. This is an open access article distributed under the Creative Commons Attribution License, which permits unrestricted use, distribution, and reproduction in any medium, provided the original work is properly cited.

The metabolic syndrome is a complex of clinical features leading to an increased risk for cardiovascular disease and type 2 diabetes mellitus in both sexes. Visceral obesity and insulin resistance are considered the main features determining the negative cardiovascular profile in metabolic syndrome. The aim of this paper is to highlight the central role of obesity in the development of a chronic low-grade inflammatory state that leads to insulin resistance, endothelial and microvascular dysfunctions. It is thought that the starting signal of this inflammation is overfeeding and the pathway origins in all the metabolic cells; the subsequent increase in cytokine production recruits immune cells in the extracellular environment inducing an overall systemic inflammation. This paper focuses on the molecular and cellular inflammatory mechanisms studied until now.

\section{Introduction}

Metabolic syndrome represents one of the major public health challenges worldwide. Different definitions are available describing overlapping but not identical population [1]. The first description goes back to 1988 when Reaven described Syndrome $\mathrm{X}$ as the association of insulin resistance, elevated glucose, hypertension, low HDL cholesterol, and augmented VLDL triglycerides [2]. However he did not include obesity, now identified as one of the essential criterion, especially visceral obesity [1].

Overweight and obesity progress to metabolic syndrome through pathophysiological mechanisms at the moment largely unclear. It has been hypothesized that the state of chronic low-grade inflammation associated with excess adipose tissue may explain the development of the obesityrelated pathologies, such as type 2 diabetes mellitus and cardiovascular disease. This inflammatory response is different from the classical responce defined by the cardinal signs of redness, swelling, heat, and pain $[3,4]$. Furthermore, it plays an important role in the development of insulin resistance that triggers the associated comorbidities of metabolic syndrome, such as atherosclerosis, dyslipidemia, hypertension, prothrombotic state, and hyperglycemia [5-8].

\section{Metabolic Syndrome}

2.1. Prevalence and Definition. The metabolic syndrome is identified as a condition of increased risk for cardiovascular disease (CVD) and type 2 diabetes mellitus (T2DM) in both sexes. Subjects with metabolic syndrome have three times risk of suffering a heart attack or stroke, twice of dying from such an event, and fivefold greater risk of developing type 2 diabetes mellitus when compared to people without the metabolic syndrome [9].

It was first described in 1920 when Kylin, a Swedish physician, demonastrated the association of high blood pressure (hypertension), high blood glucose (hyperglycaemia), and gout [10]. Later in 1947, Vague described that the visceral obesity was commonly associated with the metabolic abnormalities found in CVD and T2DM [11].

The prevalence of metabolic syndrome varies depending on the definition applied, the ethnicity, and the age of the study population. The two currently used definitions are that of the American Heart Association/National Heart, Lung, and Blood Institute (AHA/NHLBI) and the other one of the International Diabetes Federation (IDF). They describe overlapping but not identical populations. The major difference is that the first one sets the presence 
of three of five possible components, whereas the second one identifies in the waist circumference, and therefore in the abdominal obesity, the mandatory diagnostic criterion (Table 1) $[12,13]$.

Both AHA/NHLBI and IDF recognize the need of a variable definition of elevated waist circumference among different populations. The IDF suggests for Europids a threshold for increased waist circumference of at least $94 \mathrm{~cm}$ in men and $80 \mathrm{~cm}$ in women; whereas the AHA/NHLBI defines for the US population the cutoff of at least $102 \mathrm{~cm}$ for men and $88 \mathrm{~cm}$ for women (Table 1) [12,13]. Two important studies show the rationale for using different cut-off points of waist circumference in people of Asian extraction [14, 15]. East Asian and South Asian populations may have significant differences in lipid indices, fat mass as a proportion of BMI and cardiovascular morbidity. More studies are necessary to clarify these differences before consensus on separate cutoffs for waist circumference will be established for these ethnic groups [16].

\section{Metabolic Syndrome as a Risk Condition}

It is evident that a condition characterized by multiple risk factors will carry a greater risk for adverse clinical outcomes.

The so-called classic risk factors of cardiovascular disease (CVD) and coronary heart disease (CHD) include many of the components of the metabolic syndrome. The most widely applied prediction equation is the Framingham risk score, less well validated for persons with T2DM rather than without T2DM [17]. More recently, Oxford investigators have developed a risk engine based on the large UK Prospective Diabetes Study (UKPDS) database with validated CVD risk estimate for people with T2DM [18-20]. Both methods take into consideration clinical parameters, as well as age, smoking, blood pressure, and serum lipid levels. The UKPDS risk engine also includes duration of diabetes and plasma glucose levels.

\section{Obesity}

4.1. Prevalence and Definition. Obesity is a metabolic disease of pandemic proportion. The World Health Organization estimates that 300 million of adults worldwide are obese and more than 1 billion are overweight [21].

Obesity is commonly classified into subgroups depending on suspected etiology: monogenic obesity, syndromic obesity, and polygenic or common obesity [22].

The monogenic obesity is an autosomal form characterized by an extremely severe obesity in the absence of developmental delays; there are about 20 single gene disruptions that result in an autosomal form of obesity [23]. Interestingly, all these mutations position the leptin/melanocortin pathway in the central nervous system (CNS) as critical in the regulation of whole-body energy homeostasis, and obesity in these cases appears to be the result of increased appetite and diminished satiety [24].

Syndromic obesity arises from discrete genetic defects or chromosomal abnormalities at several genes, and it can be autosomal or X-linked. They are clinically obese subjects additionally distinguished by mental retardation, dysmorphic features and organ-specific developmental abnormalities; one of the most well-known forms of syndromic obesity is Prader-Willi syndrome [22].

The most common form of obesity, which affects the general population, is the polygenic form resulting from a long-term positive energy balance; the energy excess is stored in adipose tissue and, if this process is prolonged, obesity develops. The balance between energy intake and expenditure is influenced by a complex interplay of genetic, environmental, and social factors. In common obesity, some yet unclear signals lead to insulin resistance and to health risks, such as increased risk of CVD [25].

A positive energy balance or obesity can also be secondary to systemic disorders: hypothyroidism diminishes energy need, insulinoma causes obesity by promoting energy intake via recurrent hypoglycemia, and Cushing disease is associated with obesity of the classical centripetal type. Other etiological factors of obesity include the binge eating disorder, a high glycemic diet, a sedentary lifestyle, and use of certain medications like psychotropic drugs [26].

Obesity is a potent risk factor for metabolic and cardiovascular disease at the population level. At the individual patient level, however, correlations between body mass index and cardiovascular disease are not always straightforward due, in part, to differences among adipose tissue depots with respect to the overall rate of adipocyte dysfunction, tissue vascularization, and local degree of inflammation. Adipose tissue develops in several distinct anatomical depots within the body, and the differential expansion of these depots is of great importance. Expansion of visceral or abdominal white adipose tissue (WAT) has been most strongly correlated to insulin resistance and cardiovascular disease in humans and animals. Several studies have documented that peripheral adiposity (especially leg fat) may protect against cardiovascular risk $[27,28]$.

\section{Obesity and Inflammation}

One challenge aspect of metabolic syndrome is understanding the cellular mechanisms that link the metabolic abnormalities with the pathophysiological effects that later generate clinical disease.

The link between obesity and inflammation has been derived from the finding that proinflammatory cytokines are overexpressed in obesity [29].

Adipose tissue is an heterogeneous mix of adipocytes, stromal preadipocytes, immune cells, and endothelium, and it can respond rapidly and dynamically to alterations in nutrient excess through adipocyte hypertrophy and hyperplasia [30]. With obesity and progressive adipocyte enlargement, the blood supply to adipocytes may be reduced with consequent hypoxia [31]. Hypoxia has been proposed to be an inciting etiology of necrosis and macrophage infiltration into adipose tissue that leads to a overproduction of proinflammatory factors like inflammatory chemokines. This results in a localized inflammation in adipose tissue 
that propagates an overall systemic inflammation associated with the development of obesity-related comorbidities [32]. This paper will focus on three adipokine produced by macrophages: tumor necrosis factor-alpha (TNF- $\alpha$ ), interleukin-6 (IL-6), and adiponectin [33].

TNF- $\alpha$. It is a proinflammatory cytokine that exerts numerous effects in adipose tissue including lipid metabolism and insulin signaling whose circulating levels are increased with obesity and decreased with weight loss. An increase in TNF- $\alpha$ promotes the secretion of other proinflammatory cytokines IL- 6 and TNF- $\alpha$, and reduces anti-inflammatory cytokines like adiponectin [34]. Evidence suggests that TNF- $\alpha$ induces adipocytes apoptosis [35] and promotes insulin resistance by the inhibition of the insulin receptor substrate 1 signaling pathway [36].

IL-6. The primary source of circulating IL-6 is macrophages that have infiltrated WAT; IL-6 has an important role in the regulation of whole-body energy homeostasis and inflammation. Both in vitro and in vivo studies have confirmed that IL-6 is capable of suppressing lipoprotein lipase activity. IL-6 receptor is also expressed in several regions of the brain, such as the hypothalamus, in which it controls appetite and energy intake [37].

Adiponectin. Weight loss has been shown to increase adiponectin levels; in animal models of obesity and insulin resistance, its levels are reduced. Adiponectin regulates lipid and glucose metabolism, increases insulin sensibility, regulates food intake and body weight, and protects against chronic inflammation [38]. Human studies show that hypoadiponectinemia is associated with insulin resistance, hyperinsulinemia, and the possibility of developing type 2 diabetes, independent of fat mass [39].

Furthermore, more recent studies have been focused on the intracellular pathways of inflammation. In obesity, it is thought that the starting signal of inflammation is overfeeding and the pathway origins in all the metabolic cells, for example, in the adipocyte, hepatocyte, or myocyte. Studies in mice and humans evidence that consumption of nutrients may acutely evoke inflammatory responses [40, 41]. Metabolic cells, such as adipocytes, respond to this insult beginning the inflammatory response. In obese men and women, if compared with lean controls, adipose tissue and liver display an increased activation of three kinases able to induce the expression of inflammatory cytokines: the c-jun $\mathrm{N}$-terminal kinase (JNK), the inhibitor of $\mathrm{k}$ kinase (IKK), and the protein kinase R (PKR) $[42,43]$. In the same metabolic tissues, the inflammasome and the Tolllike receptors (TLRs) of the innate immune system are also activated [44-46]. Nutrients or inflammatory signals may activate the TLRs pathways and downstream JNK, IKK, and PKR. These kinases regulate downstream transcriptional programs through the transcription factors activator protein-1 (AP-1), NF- $\kappa \mathrm{B}$, and interferon regulatory factor (IRF), inducing upregulation of inflammatory mediator gene expression. The increase in cytokines exacerbates receptor activation by establishing a positive feedback loop of inflammation and the inhibitory signaling of metabolic pathways [8].

The hypothesis is that nutrients are not self and therefore elicit an immune response when metabolized, or they are naturally associated with inflammatory molecules released into the circulation $[47,48]$. In lean healthy animals, a low pulsatile inflammatory response occurs during the feeding and resolves after the nutrients are metabolized [40, 41]. In obesity or in overfeeding, responses become more intense and resolution less efficient. These signals accumulate over time and may reach a level where the professional immune cells are recruited and activated leading to an unresolved inflammatory response within the tissue $[43,45]$. The quality of diet may produce different responses: a diet rich in fruit and fibre is reported to not induce significant inflammation compared to an equicaloric high-fat diet [49].

\section{Insulin Resistance and Endothelial/Microvascular Dysfunction}

Inflammation in obesity results in the inhibition of the insulin receptor signaling cascade: the three kinases described above, JNK-IKK-PKR, can target insulin receptor substrate 1 (IRS-1) for serine phosphorilation and degradation $[6-8]$.

Insulin has important effects on the endothelium, increasing nitric oxide (NO) availability and stimulating vasodilatation [50]. In contrast, insulin resistance is associated with endothelial dysfunction. [51, 52].

Endothelial and microvascular dysfunction are present in obese subjects and represent important factors in metabolic disturbances, since they could influence both vascular resistance and insulin-mediated glucose disposal, contributing to hypertension and insulin resistance in obesity $[52,53]$.

Endothelial dysfunction is an early process in obesity: it is present even in the absence of hypertension or hyperglycemia, and it is associated with visceral obesity suggesting that obesity is an independent risk factor. It is characterized by impaired endothelium-dependent vasodilatation, reduced arterial compliance, and accelerated process of atherosclerosis [54].

It has been hypothesised an inflammatory aetiology for both obesity and atherosclerosis [55-57]. Immune cells play an important role in all stages of the atherosclerotic process [58]; in addiction, a reduction in NO, a key regulator of endothelial homeostasis, and an increase in reactive oxygen species result in endothelial dysfunction and a proatherogenic vascular bed [59].

Therefore, Gavin and collegues demonstrated a microvascular dysfunction in obese subjects resulting in a reduction on capillary density in skeletal muscle and skin when compared to lean individuals. This produces a blunted response to vasodilatation induced by oral glucose loading probably due to impaired capillary recruitment in response to an increased plasma insulin level. There is also a reduction in transcapillary delivery of insulin to muscle in obese subjects [60]. 
TABLE 1: The most widely used definitions for metabolic syndrome.

\begin{tabular}{|c|c|}
\hline $\begin{array}{l}\text { AHA/NHLBI [12]: } \\
\text { At least three of the following five features }\end{array}$ & $\begin{array}{l}\text { IDF [13]: } \\
\text { Elevated waist circumference plus any two of the other features }\end{array}$ \\
\hline Waist circumference & Waist circumference \\
\hline $\begin{array}{l}\text { (i) Non-Asian origin: } \\
\geq 102 \mathrm{~cm} \text { in men or } \geq 88 \mathrm{~cm} \text { in women }\end{array}$ & $\begin{array}{l}\text { (i) Europids, Sub-Saharan Africans, Middle Eastern: } \\
\geq 94 \mathrm{~cm} \text { in men or } \geq 80 \mathrm{~cm} \text { in women }\end{array}$ \\
\hline $\begin{array}{l}\text { (ii) Asian origin (both East and South Asians): } \\
\geq 90 \mathrm{~cm} \text { in men or } \geq 80 \mathrm{~cm} \text { in women }\end{array}$ & $\begin{array}{l}\text { (ii) both East Asians and South Asians; } \\
\text { South and Central Americans: } \\
\geq 90 \mathrm{~cm} \text { in men or } \geq 80 \mathrm{~cm} \text { in women }\end{array}$ \\
\hline & $\begin{array}{l}\text { (iii) Japanese: } \\
\geq 85 \mathrm{~cm} \text { in men or } \geq 90 \mathrm{~cm} \text { in women }\end{array}$ \\
\hline $\begin{array}{l}\text { Triglycerides (fasting) } \\
\quad \geq 150 \mathrm{mg} / \mathrm{dL} \text { or on drug therapy for high triglycerides }\end{array}$ & $\begin{array}{l}\text { Triglycerides (fasting) } \\
\geq 150 \mathrm{mg} / \mathrm{dL} \text { or on drug therapy for high triglycerides }\end{array}$ \\
\hline $\begin{array}{l}\text { HDL cholesterol } \\
<40 \mathrm{mg} / \mathrm{dL} \text { in men or }<50 \mathrm{mg} / \mathrm{dL} \text { in women or on } \\
\text { drug therapy for low HDL-C }\end{array}$ & $\begin{array}{l}\text { HDL cholesterol } \\
<40 \mathrm{mg} / \mathrm{dL} \text { in men or }<50 \mathrm{mg} / \mathrm{dL} \text { in women or on } \\
\text { drug therapy for low HDL-C }\end{array}$ \\
\hline $\begin{array}{l}\text { Blood pressure } \\
\quad \geq 130 \mathrm{mmHg} \text { systolic or } \geq 85 \mathrm{mmHg} \text { diastolic or on } \\
\quad \text { drug therapy for hypertension }\end{array}$ & $\begin{array}{l}\text { Blood pressure } \\
\geq 130 \mathrm{mmHg} \text { systolic or } \geq 85 \mathrm{mmHg} \text { diastolic or on } \\
\quad \text { drug therapy for hypertension }\end{array}$ \\
\hline $\begin{array}{l}\text { Glucose (fasting) } \\
\quad \geq 100 \mathrm{mg} / \mathrm{dL} \text { or or on drug therapy for elevated glucose }\end{array}$ & $\begin{array}{l}\text { Glucose (fasting) } \\
\quad \geq 100 \mathrm{mg} / \mathrm{dL} \text { or or on drug therapy for elevated glucose }\end{array}$ \\
\hline
\end{tabular}

AHA/NHLBI: American Heart Association/National Heart, Lung, and Blood Institute; IDF: International Diabetes Federation; HDL: high-density lipoprotein.

\section{The Effect of Different Therapeutic Approaches on Inflammatory Markers}

Considering the obesity-induced inflammatory state, studies from the literature have evaluated therapeutic interventions by interfering with inflammatory mediators.

In patients with type 2 diabetes mellitus, the pancreatic IL1-receptor antagonist (IL-1Ra) expression is reduced and high glucose concentrations induce IL-1 production in $\beta$ cells leading to impaired insulin secretion, decreased cell proliferation, and apoptosis. Larsen et al., using anakinra, a recombinant human IL-1Ra, in 70 patients with type 2 diabetes mellitus, observed after 13 weeks an improved $\beta$ cell secretory function (reduced glycated haemoglobin level, enhanced C-peptide secretion, reduced ratio of proinsulin to insulin) and a reduction of IL-6 and C-reactive protein, markers of systemic inflammation [61]. The same authors in a 39-week follow-up study investigated the durability of these responses: the reduced proinsulin/insulin ratio and CRP and IL-6 serum levels were maintained. The improvement in $\beta$-cell function could be a consequence of inhibited IL-1 signaling and not only of improved glycaemia per se [62].

In obese humans are observed increased circulating levels of TNF- $\alpha$; this event has been proposed to be causatively involved in the evolution of insulin resistance, type 2 diabetes, and its complications.

Animal studies showing that interference with TNF$\alpha$ signaling protects against developing the metabolic syndrome in obesity and studies in patients with chronic inflammatory conditions, such as rheumatoid arthritis and psoriasis, clearly show that quenching TNF- $\alpha$ activity improves insulin sensitivity $[63,64]$.

Alternatively, some studies were conducted to demonstrate the effect of TNF- $\alpha$ neutralization on insulin sensitivity in patients with type 2 diabetes: most of them indicated no appreciable effect of TNF- $\alpha$ neutralization on insulin sensitivity [65-67]. The basis for this controversy is unclear but may relate to patient populations studied or length of clinical trials; all these studies potentially did not allow sufficient time for normalization of the metabolic derangements. In fact more recently, a long-term study conducted in obese subjects with glucose alterations and subclinical inflammation treated with etanercept, TNF- $\alpha$ antagonist, found an improved fasting glucose, increased ratio of high molecular weight (HMW) adiponectin to total adiponectin, and decreased soluble intracellular adhesion molecule-1 (sICAM) [68].

However, this evidence brings to question whether in TNF- $\alpha$ is a causative link between adiposity and insulin resistance [69].

The thiazolidinediones (TZDs), a class of potent agonists of peroxisome proliferator activated receptor- $\gamma$ (PPAR $\gamma)$, increasing the activation of this transcription factor in adipose tissue, restores lipogenic function and decrease inflammation [70]. TZDs also block the ability of TNF- $\alpha$ to alter the most proximal steps of insulin signaling through the serine phosphorylation of insulin receptor and increase adiponectin expression [71]. One in vitro study demonstrated that adiponectin exerts potent immunosuppressive properties inducing the production of anti-inflammatory mediators IL-10 and IL-1 receptor antagonist (IL-1Ra) in a variety of myeloid cell types. IL-10 can inhibit the production of many other proinflammatory cytokines including IL-1, IL-2, INF $\gamma$, and TNF- $\alpha$ and impairs the phagocytic and allstimulatory capacity of macrophages [72].

In addition, adiponectin through the upregulation of IL10 increases the tissue inhibitor metalloproteinase-1 (TIMP1) levels in human macrophages preventing the extracellular degradation [73]. 


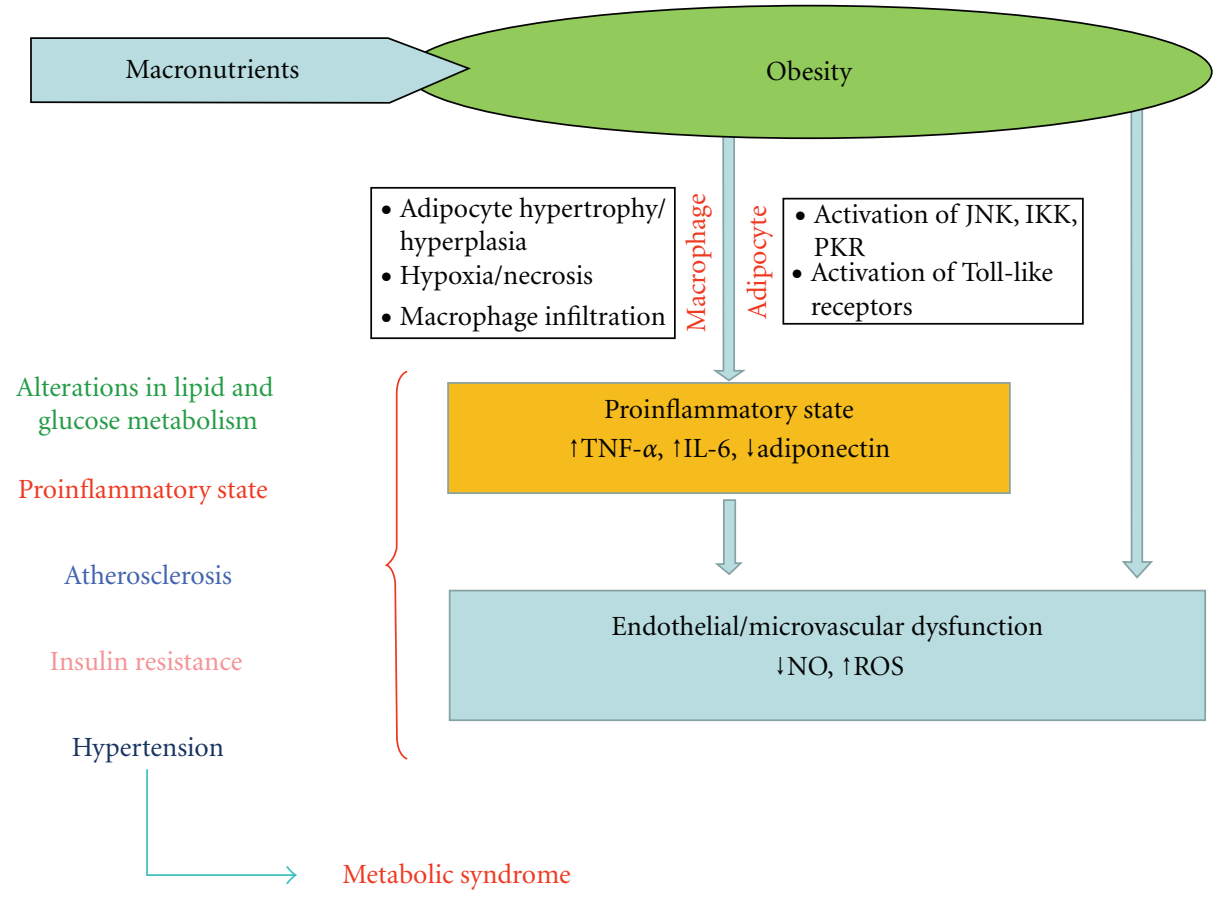

FIGURE 1: Mechanisms linking abdominal obesity and metabolic syndrome. TNF- $\alpha$ : tumour necrosis factor alpha; IL-6: interleukin 6; NO: nitric oxide; ROS : reactive oxygen species; JNK : c-jun N-terminal kinase; IKK: Inhibitor of k kinase; PKR : protein kinase R.

\section{Conclusions}

The association between visceral obesity and metabolic syndrome is well known, but the pathophysiological mechanisms that explain this link are not completely understood. Metabolic syndrome is a complex of clinical features, the most important of which is an increased visceral fat depot. Obesity results in a proinflammatory state starting in the metabolic cells (adipocyte, hepatocyte, or myocyte) and also recruiting immune cells with the consequent release of inflammatory cytokines (TNF- $\alpha$, IL- 6 , adiponectin, etc.). It has been hypothesized that the obesity-induced inflammatory process may lead to complications such as hypertension, atherosclerosis, dyslipidaemia, insulin resistance, and diabetes mellitus which characterize metabolic syndrome (Figure 1), but other studies are necessary to focus on the role of adipose tissue in the pathogenesis of diabetes mellitus and cardiovascular disease.

\section{References}

[1] R. H. Eckel, S. M. Grundy, and P. Z. Zimmet, "The metabolic syndrome," The Lancet, vol. 365, no. 9468, pp. 1415-1428, 2005.

[2] G. M. Reaven, "Role of insulin resistance in human disease," Diabetes, vol. 37, no. 12, pp. 1595-1607, 1988.

[3] R. Medzhitov, "Origin and physiological roles of inflammation," Nature, vol. 454, no. 7203, pp. 428-435, 2008.

[4] G. S. Hotamisligil, "Inflammation and metabolic disorders," Nature, vol. 444, no. 7121, pp. 860-867, 2006.

[5] G. Hu, Q. Qiao, J. Tuomilehto, B. Balkau, K. Borch-Johnsen, and K. Pyorala, "Prevalence of the metabolic syndrome and its relation to all-cause and cardiovascular mortality in nondiabetic European men and women," Archives of Internal Medicine, vol. 164, no. 10, pp. 1066-1076, 2004.

[6] G. S. Hotamisligil, D. L. Murray, L. N. Choy, and B. M. Spiegelman, "Tumor necrosis factor $\alpha$ inhibits signaling from the insulin receptor," Proceedings of the National Academy of Sciences of the United States of America, vol. 91, no. 11, pp. 4854-4858, 1994.

[7] J. M. Stephens, J. Lee, and P. F. Pilch, "Tumor necrosis factor- $\alpha$-induced insulin resistance in 3T3-L1 adipocytes is accompanied by a loss of insulin receptor substrate- 1 and GLUT4 expression without a loss of insulin receptor-mediated signal transduction," Journal of Biological Chemistry, vol. 272, no. 2, pp. 971-976, 1997.

[8] S. Boura-Halfon and Y. Zick, "Phosphorylation of IRS proteins, insulin action, and insulin resistance," American Journal of Physiology, vol. 296, no. 4, pp. E581-E591, 2009.

[9] M. P. Stern, K. Williams, C. González-Villalpando, K. J. Hunt, and S. M. Haffner, "Does the metabolic-syndrome improve identification of individuals at risk of type 2 diabetes and/or cardiovascular disease?" Diabetes Care, vol. 27, no. 11, pp. 2676-2681, 2004.

[10] E. Kylin, "Studien ueber das Hypertonie-Hyperglyca "mieHyperurika” miesyndrom," Zentralblatt fuer Innere Medizin, vol. 44, pp. 105-127, 1923.

[11] J. Vague, "Sexual differentiation. A factor affecting the forms of obesity," Presse Medicale, vol. 30, pp. S39-S40, 1947.

[12] S. M. Grundy, J. I. Cleeman, S. R. Daniels et al., "Diagnosis and management of the metabolic syndrome: an American Heart Association/National Heart, Lung, and Blood Institute scientific statement," Circulation, vol. 112, no. 17, pp. 27352752, 2005.

[13] K. G. M. M. Alberti, P. Zimmet, and J. Shaw, "The metabolic syndrome-a new worldwide definition," The Lancet, vol. 366, no. 9491, pp. 1059-1062, 2005. 
[14] G. T. C. Ko, C. S. Cockram, C. C. Chow et al., "High prevalence of metabolic syndrome in Hong Kong Chinese-Comparison of three diagnostic criteria," Diabetes Research and Clinical Practice, vol. 69, no. 2, pp. 160-168, 2005.

[15] A. Ramachandran, C. Snehalatha, and V. Vijay, "Low risk threshold for acquired diabetogenic factors in Asian Indians," Diabetes Research and Clinical Practice, vol. 65, no. 3, pp. 189195, 2004.

[16] J. L. Rosenzweig, E. Ferrannini, S. M. Grundy et al., "Primary prevention of cardiovascular disease and type 2 diabetes in patients at metabolic risk: an endocrine society clinical practice guideline," Journal of Clinical Endocrinology and Metabolism, vol. 93, no. 10, pp. 3671-3689, 2008.

[17] P. W. F. Wilson, R. B. D’Agostino, D. Levy, A. M. Belanger, H. Silbershatz, and W. B. Kannel, "Prediction of coronary heart disease using risk factor categories," Circulation, vol. 97, no. 18, pp. 1837-1847, 1998.

[18] V. Kothari, R. J. Stevens, A. I. Adler et al., "UKPDS 60: risk of stroke in type 2 diabetes estimated by the UK prospective diabetes Study risk engine," Stroke, vol. 33, no. 7, pp. 17761781, 2002.

[19] R. J. Stevens, V. Kothari, A. I. Adler, I. M. Stratton, and R. R. Holman, "The UKPDS risk engine: a model for the risk of coronary heart disease in type II diabetes (UKPDS 56)," Clinical Science, vol. 101, no. 6, pp. 671-679, 2001.

[20] R. C. Turner, H. Millns, H. A. W. Neil et al., "Risk factors for coronary artery disease in non-insulin dependent diabetes mellitus: United Kingdom prospective diabetes study (UKPDS: 23)," British Medical Journal, vol. 316, no. 7134, pp. 823-828, 1998.

[21] The World Health Report, Reducing Risk, Promoting Health Life, Geneva, Switzerland, World Health Organisation, 2002.

[22] B. M. Herrera and C. M. Lindgren, "The genetics of obesity," Current Diabetes Reports, vol. 10, no. 6, pp. 498-505, 2010.

[23] S. Orahilly, "Human genetics illuminates the paths to metabolic disease," Nature, vol. 462, no. 7271, pp. 307-314, 2009.

[24] A. P. Coll, I. S. Farooqi, B. G. Challis, G. S. H. Yeo, and S. O'Rahilly, "Proopiomelanocortin and energy balance: insights from human and murine genetics," Journal of Clinical Endocrinology and Metabolism, vol. 89, no. 6, pp. 2557-2562, 2004.

[25] F. I. Achike, N. H. P. To, H. Wang, and C. Y. Kwan, “Obesity, metabolic syndrome, adipocytes and vascular function: a holistic viewpoint," Clinical and Experimental Pharmacology and Physiology, vol. 38, no. 1, pp. 1-10, 2011.

[26] J. A. Martínez, M. J. Moreno, I. Marques-Lopes, and A. Martí, "Causes of obesity," Anales del Sistema Sanitario de Navarra, vol. 25, no. 1, pp. 17-27, 2002.

[27] J. Y. Kim, E. Van De Wall, M. Laplante et al., "Obesity-associated improvements in metabolic profile through expansion of adipose tissue," Journal of Clinical Investigation, vol. 117, no. 9, pp. 2621-2637, 2007.

[28] E. Faloia, G. Tirabassi, P. Canibus, and M. Boscaro, "Protective effect of leg fat against cardiovascular risk factors in obese premenopausal women," Nutrition, Metabolism and Cardiovascular Diseases, vol. 19, no. 1, pp. 39-44, 2009.

[29] G. S. Hotamisligil, N. S. Shargill, and B. M. Spiegelman, "Adipose expression of tumor necrosis factor- $\alpha$ : direct role in obesity-linked insulin resistance," Science, vol. 259, no. 5091, pp. 87-91, 1993.

[30] N. Halberg, I. Wernstedt-Asterholm, and P. E. Scherer, "The adipocyte as an endocrine cell," Endocrinology and Metabolism Clinics of North America, vol. 37, no. 3, pp. 753-768, 2008.
[31] S. Cinti, G. Mitchell, G. Barbatelli et al., "Adipocyte death defines macrophage localization and function in adipose tissue of obese mice and humans," Journal of Lipid Research, vol. 46, no. 11, pp. 2347-2355, 2005.

[32] P. Trayhurn and I. S. Wood, "Adipokines: inflammation and the pleiotropic role of white adipose tissue," British Journal of Nutrition, vol. 92, no. 3, pp. 347-355, 2004.

[33] K. Karastergiou and V. Mohamed-Ali, "The autocrine and paracrine roles of adipokines," Molecular and Cellular Endocrinology, vol. 318, no. 1-2, pp. 69-78, 2010.

[34] B. Wang and P. Trayhurn, "Acute and prolonged effects of TNF- $\alpha$ on the expression and secretion of inflammationrelated adipokines by human adipocytes differentiated in culture," Pflugers Archiv European Journal of Physiology, vol. 452, no. 4, pp. 418-427, 2006.

[35] J. B. Prins, C. U. Niesler, C. M. Winterford et al., "Tumor necrosis factor- $\alpha$ induces apoptosis of human adipose cells," Diabetes, vol. 46, no. 12, pp. 1939-1944, 1997.

[36] G. S. Hotamisligil, P. Peraldi, A. Budavari, R. Ellis, M. F. White, and B. M. Spiegelman, "IRS-1-mediated inhibition of insulin receptor tyrosine kinase activity in TNF- $\alpha$-and obesityinduced insulin resistance," Science, vol. 271, no. 5249, pp. 665-668, 1996.

[37] K. Stenlöf, I. Wernstedt, T. Fjällman, V. Wallenius, K. Wallenius, and J. O. Jansson, "Interleukin-6 levels in the central nervous system are negatively correlated with fat mass in overweight/obese subjects," Journal of Clinical Endocrinology and Metabolism, vol. 88, no. 9, pp. 4379-4383, 2003.

[38] M. Liu and F. Liu, "Transcriptional and post-translational regulation of adiponectin," Biochemical Journal, vol. 425, no. 1, pp. 41-52, 2009.

[39] F. Fumeron, R. Aubert, A. Siddiq et al., "Adiponectin gene polymorphisms and adiponectin levels are independently associated with the development of hyperglycemia during a 3year period: the epidemiologic data on the insulin resistance syndrome prospective study," Diabetes, vol. 53, no. 4, pp. 1150-1157, 2004.

[40] M. J. Watt, A. Hevener, G. I. Lancaster, and M. A. Febbraio, "Ciliary neurotrophic factor prevents acute lipid-induced insulin resistance by attenuating ceramide accumulation and phosphorylation of c-Jun $\mathrm{N}$-terminal kinase in peripheral tissues," Endocrinology, vol. 147, no. 5, pp. 2077-2085, 2006.

[41] A. Aljada, P. Mohanty, H. Ghanim et al., "Increase in intranuclear nuclear factor $\kappa \mathrm{B}$ and decrease in inhibitor $\kappa \mathrm{B}$ in mononuclear cells after a mixed meal: evidence for a proinflammatory effect," American Journal of Clinical Nutrition, vol. 79, no. 4, pp. 682-690, 2004.

[42] G. Solinas and M. Karin, "JNK1 and IKK $\beta$ : molecular links between obesity and metabolic dysfunction," FASEB Journal, vol. 24, no. 8, pp. 2596-2611, 2010.

[43] T. Nakamura, M. Furuhashi, P. Li et al., "Double-stranded RNA-dependent protein kinase links pathogen sensing with stress and metabolic homeostasis," Cell, vol. 140, no. 3, pp. 338-348, 2010.

[44] K. Schroder, R. Zhou, and J. Tschopp, "The NLRP3 inflammasome: a sensor for metabolic danger?" Science, vol. 327, no. 5963, pp. 296-300, 2010.

[45] H. Shi, M. V. Kokoeva, K. Inouye, I. Tzameli, H. Yin, and J. S. Flier, "TLR4 links innate immunity and fatty acid-induced insulin resistance," Journal of Clinical Investigation, vol. 116, no. 11, pp. 3015-3025, 2006.

[46] M. J. Song, K. H. Kim, J. M. Yoon, and J. B. Kim, "Activation of Toll-like receptor 4 is associated with insulin resistance in 
adipocytes," Biochemical and Biophysical Research Communications, vol. 346, no. 3, pp. 739-745, 2006.

[47] P. D. Cani, J. Amar, M. A. Iglesias et al., "Metabolic endotoxemia initiates obesity and insulin resistance," Diabetes, vol. 56, no. 7, pp. 1761-1772, 2007.

[48] C. Erridge, T. Attina, C. M. Spickett, and D. J. Webb, "A highfat meal induces low-grade endotoxemia: evidence of a novel mechanism of postprandial inflammation," American Journal of Clinical Nutrition, vol. 86, no. 5, pp. 1286-1292, 2007.

[49] P. Dandona, A. Aljada, A. Chaudhuri, P. Mohanty, and R. Garg, "Metabolic syndrome: a comprehensive perspective based on interactions between obesity, diabetes, and inflammation," Circulation, vol. 111, no. 11, pp. 1448-1454, 2005.

[50] S. A. Ritchie, M. A. Ewart, C. G. Perry, J. M. C. Connell, and I. P. Salt, "The role of insulin and the adipocytokines in regulation of vascular endothelial function," Clinical Science, vol. 107, no. 6, pp. 519-532, 2004.

[51] H. O. Steinberg, H. Chaker, R. Leaming, A. Johnson, G. Brechtel, and A. D. Baron, "Obesity/insulin resistance is associated with endothelial dysfunction: implications for the syndrome of insulin resistance," Journal of Clinical Investigation, vol. 97, no. 11, pp. 2601-2610, 1996.

[52] N. R. Villela, L. G. Kramer-Aguiar, D. A. Bottino, N. Wiernsperger, and E. Bouskela, "Metabolic disturbances linked to obesity: the role of impaired tissue perfusion," Arquivos Brasileiros de Endocrinologia e Metabologia, vol. 53, no. 2, pp. 238-245, 2009.

[53] E. Faloia, G. Giacchetti, and F. Mantero, "Obesity and hypertension," Journal of Endocrinological Investigation, vol. 23, no. 1, pp. 54-62, 2000.

[54] L. G. Kraemer-Aguiar, C. M. Laflor, and E. Bouskela, "Skin microcirculatory dysfunction is already present in normoglycemic subjects with metabolic syndrome," Metabolism, vol. 57, no. 12, pp. 1740-1746, 2008.

[55] R. Ross, "Atherosclerosis-An inflammatory disease," New England Journal of Medicine, vol. 340, no. 2, pp. 115-126, 1999.

[56] J. C. Pickup, "Inflammation and activated innate immunity in the pathogenesis of type 2 diabletes," Diabetes Care, vol. 27, no. 3, pp. 813-823, 2004.

[57] A. L. Pasqui, L. Puccetti, M. Di Renzo et al., "Structural and functional abnormality of systemic microvessels in cardiac syndrome X," Nutrition, Metabolism and Cardiovascular Diseases, vol. 15, no. 1, pp. 56-64, 2005.

[58] G. K. Hansson, "Mechanisms of disease: inflammation, atherosclerosis, and coronary artery disease," New England Journal of Medicine, vol. 352, no. 16, pp. 1685-1695, 2005.

[59] D. G. Harrison, "Cellular and molecular mechanisms of endothelial cell dysfunction," Journal of Clinical Investigation, vol. 100, no. 9, pp. 2153-2157, 1997.

[60] T. P. Gavin, H. W. Stallings, K. A. Zwetsloot et al., "Lower capillary density but no difference in VEGF expression in obese vs. lean young skeletal muscle in humans," Journal of Applied Physiology, vol. 98, no. 1, pp. 315-321, 2005.

[61] C. M. Larsen, M. Faulenbach, A. Vaag et al., "Interleukin-1receptor antagonist in type 2 diabetes mellitus," New England Journal of Medicine, vol. 356, no. 15, pp. 1517-1526, 2007.

[62] C. M. Larsen, M. Faulenbach, A. Vaag, J. A. Ehses, M. Y. Donath, and T. Mandrup-Poulsen, "Sustained effects of interleukin-1 receptor antagonist treatment in type 2 diabetes," Diabetes Care, vol. 32, no. 9, pp. 1663-1668, 2009.

[63] M. A. Gonzalez-Gay, J. M. De Matias, C. Gonzalez-Juanatey et al., "Anti-tumor necrosis factor- $\alpha$ blockade improves insulin resistance in patients with rheumatoid arthritis," Clinical and Experimental Rheumatology, vol. 24, no. 1, pp. 83-86, 2006.
[64] E. Martínez-Abundis, C. Reynoso-Von Drateln, E. HernándezSalazar, and M. González-Ortiz, "Effect of etanercept on insulin secretion and insulin sensitivity in a randomized trial with psoriatic patients at risk for developing type 2 diabetes mellitus," Archives of Dermatological Research, vol. 299, no. 9, pp. 461-465, 2007.

[65] N. Paquot, M. J. Castillo, P. J. Lefèbvre, and A. J. Scheen, "No increased insulin sensitivity after a single intravenous administration of a recombinant human tumor necrosis factor receptor: Fc fusion protein in obese insulin-resistant patients," Journal of Clinical Endocrinology and Metabolism, vol. 85, no. 3, pp. 1316-1319, 2000.

[66] H. Dominguez, H. Storgaard, C. Rask-Madsen et al., "Metabolic and vascular effects of tumor necrosis factor- $\alpha$ blockade with etanercept in obese patients with type 2 diabetes," Journal of Vascular Research, vol. 42, no. 6, pp. 517-525, 2005.

[67] L. E. Bernstein, J. Berry, S. Kim, B. Canavan, and S. K. Grinspoon, "Effects of etanercept in patients with the metabolic syndrome," Archives of Internal Medicine, vol. 166, no. 8, pp. 902-908, 2006.

[68] T. L. Stanley, M. V. Zanni, S. Johnsen et al., "TNF- $\alpha$ antagonism with etanercept decreases glucose and increases the proportion of high molecular weight adiponectin in obese subjects with features of the metabolic syndrome," Journal of Clinical Endocrinology and Metabolism, vol. 96, no. 1, pp. E146-E150, 2011.

[69] T. C. Wascher, J. H. N. Lindeman, H. Sourij, T. Kooistra, G. Pacini, and M. Roden, "Chronic TNF- $\alpha$ neutralization does not improve insulin resistance or endothelial function in "healthy" men with metabolic syndrome," Molecular Medicine, vol. 17, no. 3-4, pp. 189-193, 2011.

[70] M. Kolak, H. Yki-Järvinen, K. Kannisto et al., "Effects of chronic rosiglitazone therapy on gene expression in human adipose tissue in vivo in patients with type 2 diabetes," Journal of Clinical Endocrinology and Metabolism, vol. 92, no. 2, pp. 720-724, 2007.

[71] P. Peraldi, M. Xu, and B. M. Spiegelman, "Thiazolidinediones block tumor necrosis factor- $\alpha$-induced inhibition of insulin signaling," Journal of Clinical Investigation, vol. 100, no. 7, pp. 1863-1869, 1997.

[72] A. M. Wolf, D. Wolf, H. Rumpold, B. Enrich, and H. Tilg, "Adiponectin induces the anti-inflammatory cytokines IL-10 and IL-1RA in human leukocytes," Biochemical and Biophysical Research Communications, vol. 323, no. 2, pp. 630-635, 2004.

[73] M. Kumada, S. Kihara, N. Ouchi et al., "Adiponectin specifically increased tissue inhibitor of metalloproteinase-1 through interleukin-10 expression in human macrophages," Circulation, vol. 109, no. 17, pp. 2046-2049, 2004. 


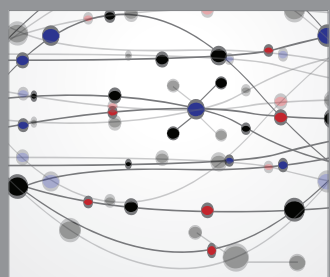

The Scientific World Journal
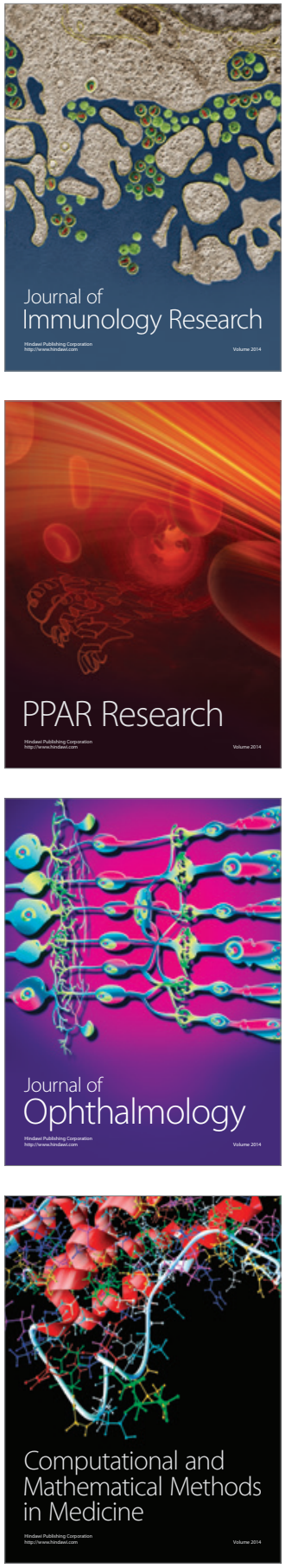

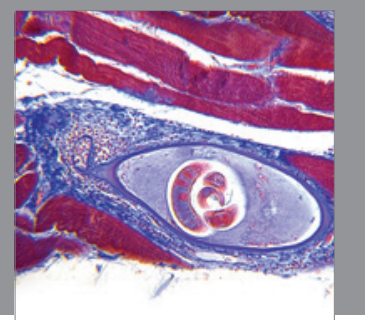

Gastroenterology

Research and Practice
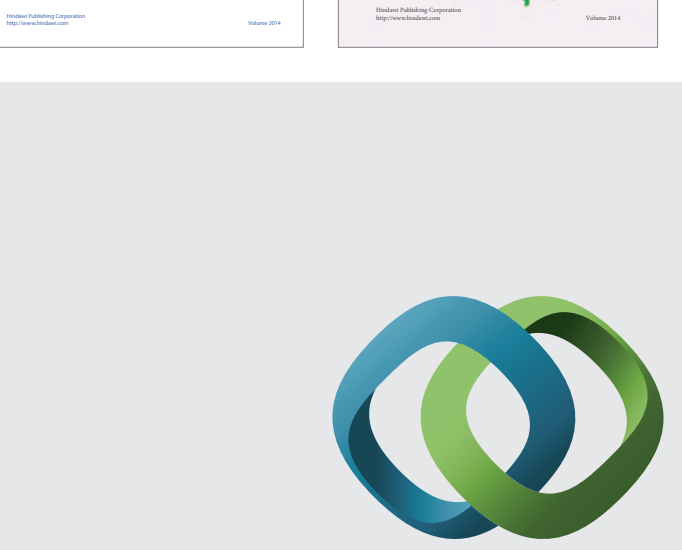

\section{Hindawi}

Submit your manuscripts at

http://www.hindawi.com
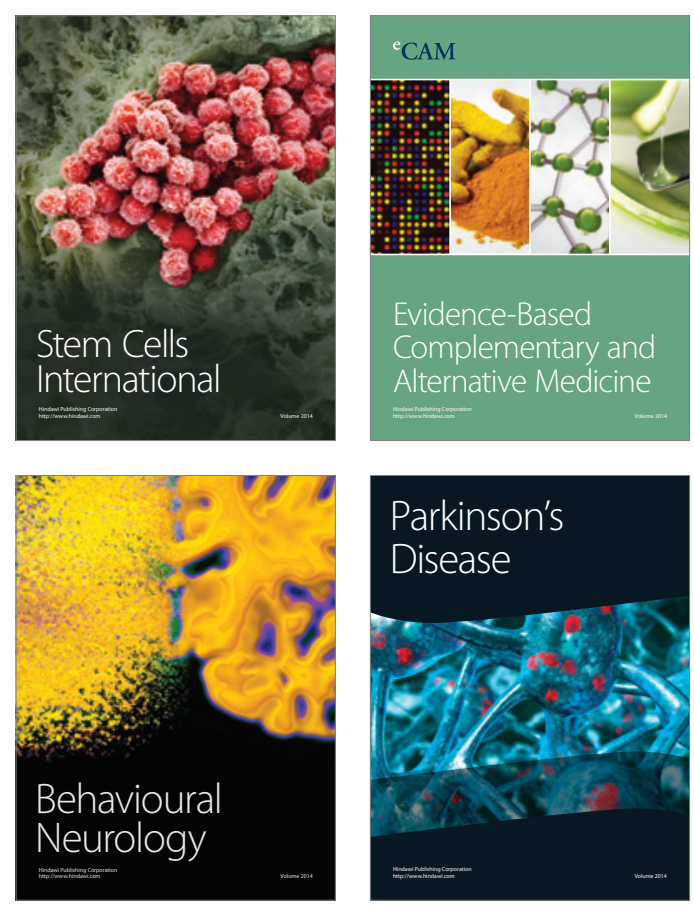

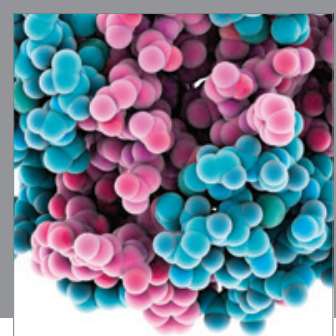

Journal of
Diabetes Research

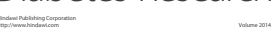

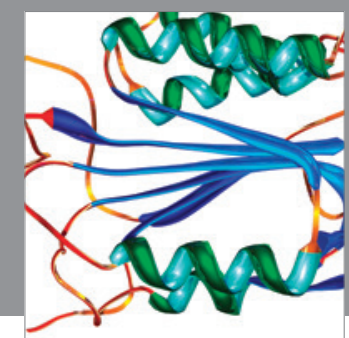

Disease Markers
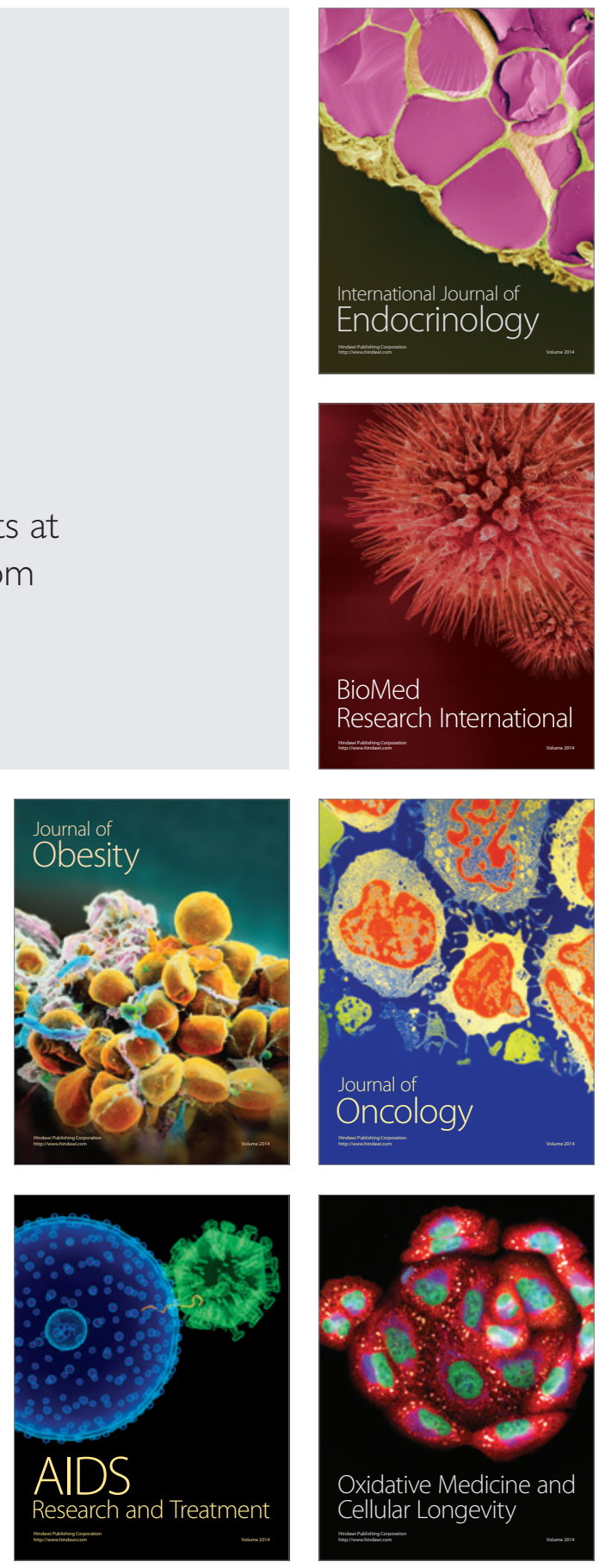